DOI 10.37882/2500-3682.2021.04.19

\title{
СПЕЦИФИКА УСТАНОВЛЕНИЯ МЕЖЛИЧНОСТНОГО КОНТАКТА У ИНСПЕКТОРА ПО ДЕЛАМ НЕСОВЕРШЕННОЛЕТНИХ С РОДИТЕЛЯМИ ПОДРОСТКОВ
}

\section{THE SPECIFICS OF THE INTERPERSONAL CONTACT OF THE INSPECTOR \\ OF JUVENILE AFFAIRS WITH THE PARENTS OF ADOLESCENTS}

N. Sysa

Summary: For any State, the issues of ensuring the protection of the family and childhood are a priority. An important intermediary for ensuring the rights of minors, as well as conducting preventive work to prevent juvenile delinquency, is the Juvenile Affairs Unit. It is it that provides legal protection of minors on behalf of the State. Modern psychological theories justify the role of psychological contact in social interaction. However, their application in relation to the "inspector-parent" requires taking into account the specific socio-psychological context, as a rule, characterized by the reluctance and resistance of parents raising a minor child to build a trusting relationship with the inspector. When establishing interpersonal contact, juvenile inspectors face a difficult task: on the one hand, to implement punitive measures against young offenders or persons who have committed offenses against minors, on the other, in order to monitor families, to maintain long-term relationships with them. However, in order to carry out their official duties, contact between the inspector and the parents of teenagers is necessary. Based on the review and theoretical analysis of the literature, the article examines the specific features of establishing interpersonal contact between the inspector of juvenile affairs and the parents of adolescents. The issue of interaction between the "inspector-parent" from the position of "forced contacts" is also considered. The question of the formation of professional skills of inspectors of juvenile affairs is raised. Based on the existing scientific concepts in theory and taking into account the specific features of the interaction of the inspector of juvenile affairs with the parents of adolescents, an algorithm for establishing interpersonal contact in relation to the inspector-parent is developed.

Keywords: social interaction, interpersonal contact, the concept of forced contacts, juvenile delinquency, juvenile delinquency, inspector of juvenile affairs, professional competencies, formation of professional skills, psychological barriers specifics of establishing contact.

\author{
Сыса Наталия Владимировна \\ Соискатель, Российский государственный \\ социальный университет \\ nataslip@list.ru
}

Аннотация: Для любого государства вопросы обеспечения охраны семьи и детства являются приоритетными. Важным посредником по обеспечению прав несовершеннолетних, а также проведения профилактической работы по предупреждению подростковой преступности является подразделение по делам несовершеннолетних. Именно оно от лица государства обеспечивает правовую защиту несовершеннолетних граждан. Современные психологические теории обосновывают роль психологического контакта в социальном взаимодействии. Однако их применение в отношении «инспектор-родитель» требует учета специфического социально- психологического контекста, как правило, характеризующегося нежеланием и сопротивлением родителей воспитывающих несовершеннолетнего ребенка к выстраиванию доверительных отношений с инспектором. При установлении межличностного контакта, перед инспекторами по делам несовершеннолетних встает непростая задача: с одной стороны, осуществлять меры карательного характера к юным правонарушителям или лицам, совершившим правонарушения в отношении несовершеннолетних, с другой, в целях осуществления контроля за семьями, поддерживать с ними доверительные отношения. Тем не менее, для осуществления своих должностных обязанностей, контакт между инспектором и родителями подростков необходим. В статье на основе обзора и теоретического анализа литературы рассматриваются специфические особенности установления межличностного контакта у инспектора по делам несовершеннолетних с родителями подростков. Также вопрос взаимодействия «инспектор-родитель» с позиции «рассматривается вынужденных контактов». Поднимается вопрос формирования профессиональных навыков инспекторов по делам несовершеннолетних. На основе существующих в теории научных концепций и с учетом специфических особенностей взаимодействия инспектора по делам несовершеннолетних с родителями подростков, разработан алгоритм установления межличностного контакта в отношении инспектор-родитель.

Ключевые слова: социальное взаимодействие, межличностный контакт, концепция вынужденных контактов, подростковая преступность, правонарушения несовершеннолетних, инспектор по делам несовершеннолетних, профессиональные компетенции, формирование профессиональных навыков, психологические барьеры, специфика установления контакта.

ют специфические особенности. В первую очередь речь ведется о приоритете выбора дистанционных форм в предпочтении живому общению. А поскольку дистанционная форма общения имеет ряд своих особенностей, по многим признакам уступающая непосредственному контакту, то и установление контакта в данных условиях претерпевает весомые изменения. Исходя из сложившихся обстоятельств, все большую актуальность приоб- 
ретает тема психологических барьеров в установлении межличностных контактов. В нашей статье мы освещаем тему специфики межличностного контакта инспектора по делам несовершеннолетних с родителями подростков, поэтому направление исследования рассматривается при взаимодействии «инспектор - родитель». Почему же данная категория представляет интерес для общества? Прежде всего, стоит отметить, что вопросы, связанные с обеспечением защиты и поддержки детей как будущего общества являются приоритетными для любого государства.

\section{$* * *$}

Сфера правовой защиты несовершеннолетних, а также обеспечение надлежащих условий для предупреждений асоциального поведения подрастающего поколения, охватывает весьма значимую часть в формировании будущего общества. Исследования в этой области позволят получить в итоге продукт, улучшающий качество работы инспекторов по делам несовершеннолетних при выполнении своих служебных обязанностей. Однако, ставя такие задачи, необходимо учитывать специфические особенности работы инспектора по делам несовершеннолетних, при взаимодействии с родителями, воспитывающими несовершеннолетнего подростка или лицами осуществляющими данную функцию.

Специфика взаимодействия инспектора по делам несовершеннолетних с родителями подростков нередко носит конфликтный характер. Зачастую основанием для установления контакта между инспектором по делам несовершеннолетних с родителями подростков являются факторы, которые нежелательны или неблагоприятны для его сторон. Основание для вмешательства инспектора в семью - это складывающиеся неблагоприятным образом обстоятельства в отношении несовершеннолетнего. К их числу можно отнести: возникновение у несовершеннолетнего проблем, связанных с учебой или условиями проживания, совершение несовершеннолетним правонарушения, риски его совершения, незаконные действия в отношении несовершеннолетнего, в том числе и со стороны его родителей или законных представителей.

В большинстве случаев инспектор по делам несовершеннолетних выполняет свои профессиональные задачи в затрудненных условиях межличностного взаимодействия. Чаще всего, причиной обращения инспектора в семью, является факт совершения правонарушения, что само по себе негативным образом сказывается на установлении контакта между инспектором по делам несовершеннолетних с родителями подростка. Из-за обоюдно нежелательных обстоятельств контакт между инспектором и родителями подростка с одной стороны воспринимается как необходимость, с другой же сталки- вается со значительным сопротивлением. Прежде всего, инспектор по делам несовершеннолетних выполняет задачи по предупреждению, недопущению и пресечению правонарушений в отношении несовершеннолетних. Но помимо этого, для эффективного осуществления своей деятельности, инспектору надлежит обладать умением найти правильный подход к своим подопечным, установить межличностный контакт с ними, чтобы иметь возможность в последующем осуществлять правовую защиту и правовой контроль.

Для реализации своей основной профессиональной задачи инспектору ПДН необходимо, наряду с осуществлением карательных мер в отношении несовершеннолетнего, выстроить отношения с подростком, его семьей, ближним окружением таким образом, чтобы у инспектора была возможность дальнейшего взаимодействия. Чтобы вывести отношения из русла нежелательной неизбежности в русло осознанной необходимости, инспектору по делам несовершеннолетних необходимо установить психологический контакт со своими подопечными. Межличностный контакт предполагает взаимное стремление его участников поддерживать общение. Обращаясь к определению понятия контакт пришедшего из латинского contactus (соприкосновение), образованное от глагола contingō (прикасаться, брать, трогать), можем подытожить, что контакт подразумевает такую форму взаимодействия, при которой между инспектором по делам несовершеннолетних и родителем подростка возникнут «точки соприкосновения» для осуществления обоюдной цели - обеспечение правовой защиты и безопасности несовершеннолетнего. При условии, что родители подростка сами не относятся к категории асоциальных семей и заинтересованы в благополучии своего несовершеннолетнего подростка, инспектор по делам несовершеннолетних и родитель подростка имеют общую цель. Эта цель как раз может стать отправной точкой при установлении межличностного контакта и являться основным мотиватором к контакту.

Итак, специфическая составляющая взаимоотношений «инспектор-родитель» заключается в негативно заряженной основе. В случае совершения правонарушения несовершеннолетним, карательные меры лишь в исключительных случаях воспринимаются семьей несовершеннолетнего положительно. Чаще всего сам факт взаимодействия с инспектором по делам несовершеннолетних воспринимается семьей, воспитывающей несовершеннолетнего, отрицательно. Что уж говорить о случаях, когда сами родители ведут асоциальный образ жизни, не выполняют свои родительские обязанности и являются правонарушителями в отношении своего собственного ребенка. В данном случае целесообразно вести речь об установлении контакта в условиях вынужденности или упомянуть о таком понятии как «вынужденный контакт» 
Одной из основных задач инспектора по делам несовершеннолетнего является эффективность осуществления им своих профессиональных задач, его социальнопсихологическая компетентность. Рассматривая вопрос о профессиональной компетентности инспектора по делам несовершеннолетних, прежде всего мы будем основываться на наличии знаний, опыта и навыков, позволяющих инспектору эффективно осуществлять свою профессиональную деятельность. Коммуникация как вид деятельности имеет собственную структуру, где контакт выступает в качестве наиболее важной первой ступенью на пути к взаимодействию. Тем самым контактность инспектора по делам несовершеннолетних является одной из наиболее значимых качеств, характеризующих инспектора по делам несовершеннолетних как компетентного специалиста [4].

Исследованием межличностного контакта, а также проблемами установления контакта занимались отечественные и зарубежные ученые: Н.В. Куницина, А.А. Леонтьев, О.И. Миронова, В.Н. Мясищев, Б.Д. Парыгин,

A.B. Петровский Л.Б. Филонов, Adler R.B., Durrheim K, Guilford Y.P., Köhler W., Lewin K., Rogers, C.R. и др.

Результаты анализа исследований ряда отечественных и зарубежных ученых позволяет вывести ряд факторов определяющих контактность человека:

1. Прежде всего, это умение воспринимать, ориентироваться в процессе общения, выявлять значимые компоненты реагирований собеседника, взаимодействовать с ним.

2. Второе предполагает умение устанавливать контакт при всем многообразии его средств. Обладать необходимым набором знаний на предмет контактности, обладать умением применения различных методов по установлению контакта.

3. Эмоционально-волевая устойчивость и лабильность при установлении контакта. Умение использовать все свои возможности и воздерживаться от негативных проявлений эмоций, которые могут стать помехой в установлении контакта.

4. Коммуникативные навыки, позволяющие наиболее продуктивно использовать свои ораторские навыки, эффективно осуществлять процессы приема, раскодировки и передачи информации собеседнику, учитывая его индивидуально-личностные особенности, что позволит максимально доводить необходимую информацию до оппонента.

5. Организаторские и лидерские качества, позволяющие инспектору по делам несовершеннолетних держать процесс установления контакта с родителями несовершеннолетних под своим контролем, при необходимости направлять его в необходимое русло, избегать возможных барьеров и проблем, руководить всем процессом установления контакта.
6. Эмпатия, доброжелательность и внимательность по отношению к собеседнику, способность создавать позитивный эгрегор при установлении контакта.

В концепции К. Роджерса имеется такое понятие как конгруэнтность - согласованность информации передаваемой человеком. Роджерс полагал, что важными условиями контакта являются конгруэнтность, эмпатия и позитивное принятие личности. Латинское слово «congrū̄» в дословном переводе означает «согласие», «совпадение»[13]. В более широком значении под конгруэнтностью понимается соответствие внутренних переживаний человека с его внешними проявлениями. В социальной психологии конгруэнтность в общении предполагает соответствие передаваемой человеком информации с невербальными формами его поведения во время передачи информации. Известно, что невербальные формы общения человека более информативны и правдивы, нежели сама передаваемая информация. Каждый человек обладает способностью считывать невербальные сигналы своего собеседника на подсознательном уровне. Таким образом, при наличии неконгруэнтности, человек, не осознавая истинных причин, может испытывать чувство дискомфорта и контакт может быть прекращен. В таком случае, собеседник не всегда сможет объяснить причины своего нежелания идти с неконгруэнтным партнером на контакт, испытывая при этом не осознаваемый им дискомфорт. Интересно, что в английском языке слово «конгруэнтность» определяется как честность или открытость, поскольку упомянутое выше несоответствие вербальных и невербальных сигналов, как раз-таки, свидетельствует о неискренности партнера и его стремлении продемонстрировать собеседнику свое не соответствующее действительности состояние, настроение и т.д.

В отечественной психологии контакт рассматривается в качестве неотъемлемой составляющей межличностного общения. А контактность человека - важный фактор способности к эффективному взаимодействию.

Исходя из концепции Л.Б. Филонова под психологическим контактом понимается характер отношений между его участниками. Наиболее значимыми качествами при этом Л.Б. Филонов отмечает доверительность, стремление к сближению, стремление совершать благо для другого и пр.

Кроме того, Филонов отмечает, что доверительное общение является залогом успешного установления контакта, которое, в свою очередь, приносит свои плоды в виде готовности к открытому общению, искренности, открытости, стремлении к совместному взаимодействию, стремлении этот контакт поддерживать [16].

Задачей инспектора является выстраивание обще- 
ния с родителем подростка таким образом, чтобы вызвать в нем потребность в установлении и поддержании контакта с инспектором. А для этих целей эффективными будут идеи методики Л.Б. Филонова. Рассмотрение контактного взаимодействия в рамках концепции Л.Б. Филонова, позволяет инспектору по делам несовершеннолетних, опираясь на научные знания в области психологии общения, выстроить четкий алгоритм своих действий для установления контакта с родителями подростка с учетом специфики данного взаимодействия и его конфликтной составляющей. Данная стратегия позволяет избежать «острых углов» организационных и психологических проблем. Согласно данной концепции, контактирующие в процессе установления контакта совместно проходят ряд стадий, за счет которых осуществляется межличностный контакт [16].

Идею Л.Б. Филонова об особенностях установления контакта в рамках концепции вынужденных контактов развила в своей научной деятельности О.И. Миронова. Суть данной концепции заключается в установлении контакта в условиях, когда контакт между его участниками неприятен, нежелателен, но необходим. В таком случае участники контакта осознают, что необходимость этого взаимодействия стоит выше личного отношения и собственных переживаний по этому поводу. Таким образом, контактирующие сознательно делают выбор в пользу установления контакта держа в приоритете ожидаемую от контактного взаимодействия цель[9].

Оценивая контингент под учётных лиц, специфику семей, состоящих на учете у инспектора, основная ответственность за установление и поддержание контакта у инспектора по делам несовершеннолетних с родителями подростка лежит на инспекторе. И от того насколько инспектору удастся замотивировать родителя на контакт с ним, зависит успешность осуществления инспектором своей профессиональной задачи. Нередки случаи, когда инспектору приходится иметь дело с ассоциальными, дезадаптивными семьями. Причин тому может быть множество: дезадаптация членов этих семей, различные нарушения социализации и воспитательных процессов подопечных лиц, наличие различных психологических травм, наличие проблем, связанных с психическими нарушениями, различного рода расстройствами, наличием проблем, связанных с карательными мерами в отношении семьи, совершившей правонарушение и др. Анализируя эти обстоятельства становится несложным сделать вывод о специфической форме установления контакта у инспектора по делам несовершеннолетних с родителями подростков. Инспектору надлежит не только учитывать все возможные препятствия на пути к установлению контакта, но и обладать умениями при всех этих осложнениях замотивировать родителя на контакт. Для этого инспектору просто необходимо в совершенстве обладать коммуникативными навыками, владеть приемами убеждения, уметь правильно считывать информацию о собеседнике, находить каналы его восприятия и используя соответствующие приемы, выводить родителя на контактное взаимодействие.

С другой стороны, инспектор по делам несовершеннолетних должен также выступить в качестве инструктора при взаимодействии с родителем и помочь ему наладить контакт с ребенком. Поделиться знаниями в этой области с родителем, обучить конкретным методикам, направленным на восстановление контакта в детско-родительских отношениях. Осуществлять работу по формированию позитивных отношений между родителями и их несовершеннолетними детьми.

Наряду с этим, инспектор осуществляет непрерывную индивидуальную работу, развивает профессиональные навыки, толерантность, устойчивость - все качества, необходимые для выполнения своих профессиональных задач.

Таким образом, мы видим насколько работа инспектора по делам несовершеннолетних многозадачна и разнопланова. В связи с этим инспектору ПДН требуется специальным образом разработанная программа, включающая в себя конкретные шаги по разрешению всех вышеупомянутых задач.

В рамках нашей темы, рассмотрим шаги согласно концепции Л.Б. Филонова с выведением алгоритма последовательных действий, который может быть применен инспектором при установлении контакта с родителями подростка.

1. На уровне подготовительной стадии при взаимоотношении инспектор - родитель необходимо развить общую мотивацию к общению у оппонентов. Для выполнения этой задачи реализуются такие психологические приемы как: активное слушание, эмпатия, выражение согласия с партнером, поиск совместных точек соприкосновения, отсутствие критических замечания, резких оценочных суждений и т.д.

Вторая стадия характеризуется поиском общих интересов по обсуждаемому вопросу. У инспектора по делам несовершеннолетних при взаимодействии с родителями общие интересы могут быть сосредоточены на интересах несовершеннолетнего, его основных потребностях и вопросах его правовой защиты.

Третья стадия заостряет внимание на позитивных подкреплениях собеседника, подбадриваний, позитивной картины предполагаемого результата от совместной деятельности и т.д. Инспектор по делам несовершеннолетних в качестве позитивных подкреплений может обозначать родителю успешные результаты их контактного 
взаимодействия.

Четвертая стадия посвящена совместному обсуждению общей проблематики поднимаемого вопроса. Эта же стадия может быть использована для возможности критического выражения сторонами собственных мыслей, чувств, переживаний, касаемо обсуждаемого вопроса.

Пятая стадия предполагает обсуждение изменений, вызванных установлением контакта.

Шестая стадия является формированием совместными усилиями участников контакта общего продукта в виде конкретного алгоритма действий, направленных на разрешение возникшей проблемы, послужившей основанием установления контакта.

\section{Зак^ючение}

Таким образом, благодаря освещению темы установления межличностного контакта у инспектора по делам несовершеннолетних с родителями подростка, можно выявить специфические особенности установления межличностного контакта во взаимодействии «инспектор- родитель». Прежде всего - это условия, в которых инспектору по делам несовершеннолетних приходится осуществлять свою профессиональную деятельность. Поскольку основанием для установления контакта у инспектора по делам несовершеннолетних чаще всего является правонарушение в отношении несовершеннолетнего лица, то взаимодействие инспектора с родителями, воспитывающими несовершеннолетнего подростка, нередко выстраивается в непростых конфликтных отношениях. Кроме того, возникновение обстоятельств, послуживших поводом для встречи с инспектором, нередко оборачиваются для родителя карательными мерами в виде наложения административного взыскания, составления на родителя несовершеннолетнего административного протокола по статье 5.35 КоАП РФ «Неисполнение или ненадлежащее исполнение родителями или иными законными представителями несовершеннолетних обязанностей по содержанию, воспитанию, обучению, защите прав и интересов несовершеннолетних». Данная мера влечет наложение на родителя административного штрафа в соответствии с законодательством РФ. А в особо серьезных случаях или повторном совершении административного правонарушения вплоть до административного ареста в отношении родителя [6]. Более того, при совершении правонарушения в отношении несовершеннолетнего, семья автоматически ставится на учет в подразделении по делам несовершеннолетних минимум на пол года, что также воспринимается родителями воспитывающими несовершеннолетнего ребенка негативно. Безусловно, в таких условиях инспектору бывает крайне сложно поддерживать с родителем контакт на протяжении длительного времени. Поэтому инспектору по делам несовершеннолетних необходим инструмент, позволяющий, на основе учета всех специфических особенностей работы инспектора, устанавливать контакт с родителями подростка. Кроме того, на основе анализа теоретического материала, инспектору по делам несовершеннолетних требуется специально разработанная программа, направленная на совершенствование его профессиональных навыков с обозначением психологических приемов и упражнений, позволяющих инспектору освоить азы эффективного межличностного взаимодействия, развития коммуникативных навыков, владение инструментом методов убеждения, осваивание навыка психологической диагностики, опираясь на невербальные формы взаимодействия.

\section{ЛИТЕРАТУРА}

1. Бодалев А.А. Психология общения. - М.: Издательство «Институт практической психологии», Воронеж: НПО «МОДЭК», 1996. - 256 с.

2. Большой толковый психологический словарь / А. Ребер. - М.: Вече - Аст, 2001. - 2т. - 399с.

3. Воробьева Е.А. Профессионально-психологические особенности контактности следователей в условиях допроса: дис. .... канд. психол. наук. - М.: 2003.266 с.

4. Зимняя И.А. Социально-профессиональная компетентность как целостный результат профессионального образования (идеализированная модель) // Проблемы качества образования. Кн. 2. М.: ВЛАДОС, 2005. С. 21-26., С.23

5. Ильин Е.П. Психология общения и межличностных отношений / Е.П. Ильин. - СПб.: Питер, 2014. - 576 с.

6. К Кодекс Российской федерации об административных правонарушениях 030.12 .2001 № 195-Ф3 (ред. от 09.03.2021) - Электронный ресурс. Режим доступа: http://www.consultant.ru/document/cons_doc_LAW_34661/8c909d7721 021e06a0c (26.03.2021)

7. Леонтьев А.А. Психология общения: учебное пособие для студентов вузов, обучающихся по специальности «Психология» / А.А. Леонтьев. - 5-е изд., стер. - М.: Смысл: Academia, 2008. - 365 с.

8. Маслоу А. Мотивация и личность.: 3-е изд. / Пер с англ. - СПб.: Питер, 2011. - 352 с.

9. Миронова, 0.И. Вынужденный контакт как вид межличностного контакта / О.И. Миронова. - М.: ИПКгосслужбы, 2008.

10. Миронова, 0.И. Субъектно-психологическая концепция вынужденных контактов / 0.И. Миронова. - 2-е изд., испр. и доп. - Москва: Белый ветер, 2018. - 306 с.

11. Ожегов, С.И. Толковый словарь русского языка: около 100000 слов терминов и фразеологических выражений / С. И. Ожегов; под редакцией Л.И. Скворцова. - 28-е изд., перераб. - М.: Мир и образование, 2018. - 1375 с. 
12. Парыгин, Б.Д. Социальная психология: Учеб. пособие для студентов вузов, обучающихся по направлению и специальностям психологии / Б.Д. Парыгин. - СПб.: СПбГУП, 2003. -615 с.

13. Роджерс, К.Р. Становление личности. Взгляд на психотерапию: [перевод] / К.Р. Роджерс. - Москва.: ИОИ, 2017. - 237 с.

14. Сетраков А.Н., Довгань Е.А. Речевая культура как главная составляющая служебного общения сотрудника органов внутренних дел // Colloquium- journal. 2019. № 7-4 (31). C. 34-35. URL: http://www.colloquium- journal.org/wp-content/uploads/2019/04/Colloquium-journal-731-chast-4.pdf.

15. Тигунцева Г.Н. Генезис психологического знания о феномене установления контакта и его использования в преодолении коммуникативных деструкций / Г.Н. Тигунцева // Вестник ИрГТУ, №12, 2014. - 362-369 с.

16. Филонов Л.Б. Контактология как основа общения в будущем // Общение- 2006: на пути к энциклопедическому знанию: Материалы конференции 19-21 октября 2006. Психологический институт РАО. М.: Академия имиджелогии, 2006. 564 с.

17. Энциклопедический словарь. Психология Общения. / Под общ. ред. А.А. Бодалева. - М.: Изд-во «Когито-Центр», 2011 г. - Электронный ресурс. Режим доступа: https://984.slovaronline.com/ (02.06.2019).

18. Durrheim, K., Dixon J. Racial encounter: The social psychology of contact and desegregation. Routledge, 2013.Guilford Y.P. (1967). The nature of human intelligence. New York: Mc-Graw Hill, 327 p.

19. Hargie 0. Skilled interpersonal communication: Research, theory and practice. London : Routledge, 2016. 658 p. https://doi.org/10.4324/9781315741901 (03.06.2019r.)

20. Köhler, W. Gestalt psychology // Psychol. 1967. Forsch. 31,XVIII-XXX. doi:10.1007/BF00422382

21. Lewin, K. Principles of Topological Psychology. N. Y.: McGraw Hill, 1936. 231 p.

(c) Сыса Наталия Владимировна (nataslip@list.ru).

Журнал «Современная наука: актуальные проблемы теории и практики»

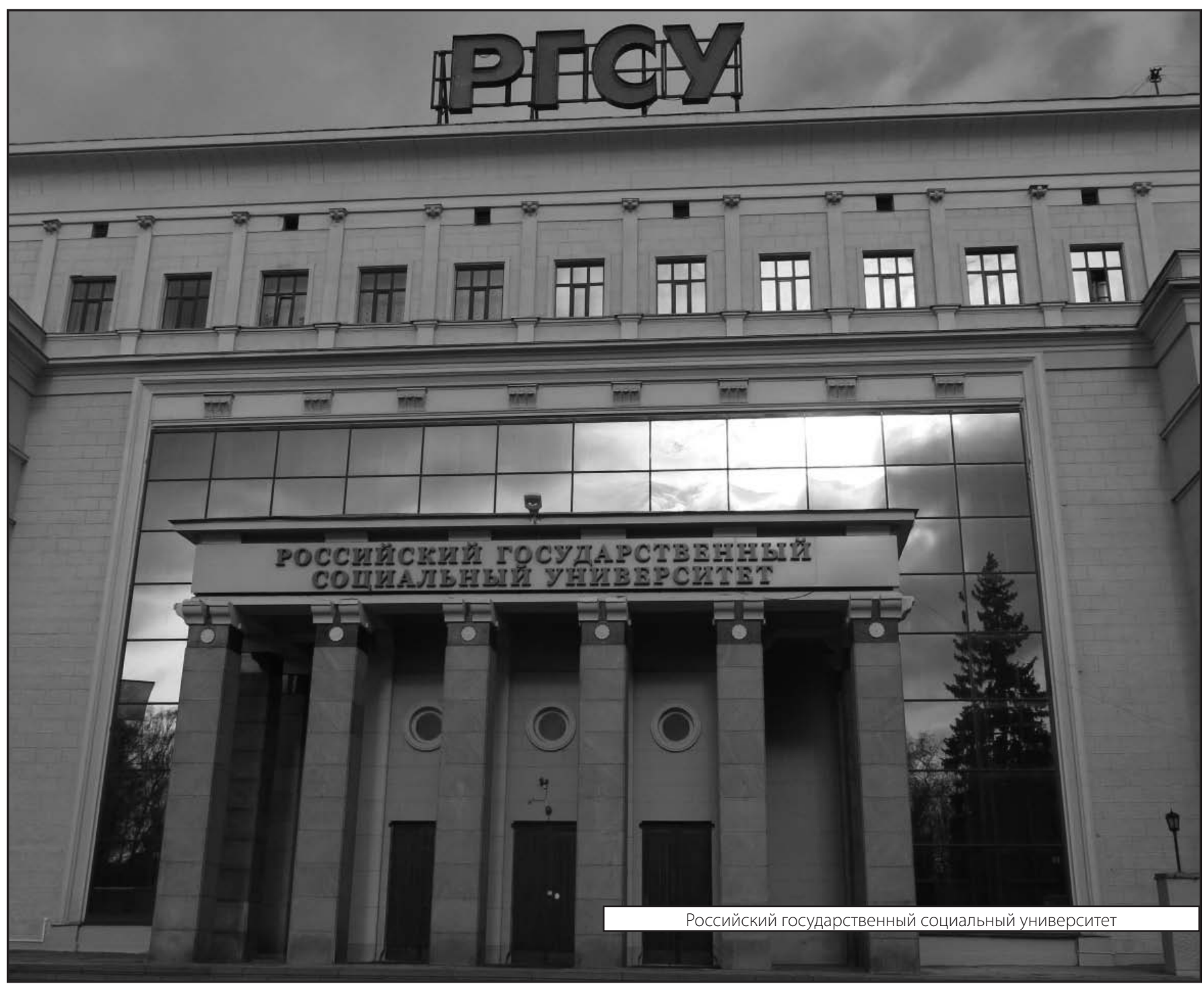

